\title{
The Relation between Prospective Teachers' Attitudes towards Uncertainty and Motivation in Teaching
}

\author{
Cem Şenol * (i) and Mustafa Akdağ \\ Department of Education Science, Inonu University, 44000 Malatya, Turkey; mustafa.akdag@inonu.edu.tr \\ * Correspondence: cemsenol023@gmail.com; Tel.: +90-422-377-3000
}

Received: 11 July 2018; Accepted: 14 August 2018; Published: 17 August 2018

\begin{abstract}
The aim of this study is to determine the relationship between prospective teachers' attitudes towards uncertainty and their motivation in teaching. The research was conducted with a correlational model. In this study, exploratory and predictive correlation techniques were used. The study group was comprised of 396 fourth grade students studying at the Inonu University Faculty of Education in the academic year of 2015-2016. A simple linear regression analysis and Pearson Product Moment analysis were conducted on the obtained data. A moderate negative and significant relationship was found between prospective teachers' attitudes towards uncertainty and their motivation in teaching, and the attitude towards to uncertainty was observed to be a significant predictor of motivation in teaching. In addition to this, a moderate negative significant relationship was found between prospective teachers' attitudes towards uncertainty and their intrinsic and extrinsic motivation, and the attitudes towards to uncertainty was observed to be a significant predictor of the intrinsic and extrinsic motivation.
\end{abstract}

Keywords: motivation in teaching; attitudes towards uncertainty; teacher training; regression analysis

\section{Introduction}

The changes in current technological and scientific areas also bring about a change in the expectations and needs of individuals. At the point of meeting these expectations and needs, the motivation of the individuals appears as a crucial subject to be approached. The concept of motivation strongly felt at every stage of life is vital to be addressed in the educational institutions whose input and output are human, social benefits are quite high and by this aspect which are non-profit and constitute a different structure than others [1]. From the point of view of education, motivation is students' active participation in a subject that they need to wonder about and become interested in. As it is seen, the most prominent feature of motivation is its leading individuals to specific purposes and activating them in the pursuit of these goals [2]. When the concepts of motivation in education are considered, the motivation and willingness of a student who is in the learning process usually comes to mind. However; rather than learning, desire and enthusiasm which are required to teach are important, too [3]. The reason is teachers' appearance in person, enthusiasm, and motivation in teaching process similarly affects the learning process of students. According to Brophy, the biggest reason for failure in a school environment is the lack of motivation of teachers and students [4]. To implement teaching and learning processes in a proper way, the teachers' willingness is required; that is to say, the teacher must be highly motivated, eager, enthusiastic, innovative, modern, and inspiring. Besides, according to research done by Atkinson [5], it is stated that rather than their professional competence, teachers' motivation levels play a significant role on students' learning. Consequently, educational institutions' capability to provide education of a desired quality is closely associated with the willingness and success of the teachers. Teachers working more efficiently and willingly depend on the process of motivation, though. This situation reveals the necessity that teachers and prospective teachers in these institutions should be motivated for their profession and their current level of motivation must be increased. In other words, one of the basic components of the phenomenon 
of education is that the teachers take significant responsibilities of training individuals in a qualified manner in accordance with the requirements of this era. Being able to perform these responsibilities and advancing the quality of the education system necessitate their motivation to be high in their profession (teaching) prior to service. However, the uncertainties about candidate teachers' appointment, in other words, whether they can perform their profession or not, and the thoughts about that teaching profession loses its prestige for the public, because candidate teachers consider these unpredictable situations as source of danger and perceive negative events about the future as threats and unacceptable situations.

Due to human nature, mankind wants to be sure of the future and to guarantee it [6]. When individuals think they cannot reach their achievable long-term goals, despair starts to grow and they find themselves in an ambiguous situation [7]. Uncertainty emerges when an event that develops unexpectedly affects individuals negatively. Generally, uncertainty is defined as ambiguity of expressions, variability of conditions, or various interpretations and views that may be contradictory at times [6]. Uncertainty is an event that is a threat for people, because uncertainty deprives people of how they can act in a given situation and the confidence they have in knowing what they can expect from their physical and social environment. For this reason, people look for ways to remove uncertainty or reduce it to a tolerable level or manage it cognitively. In order to manage uncertainty and renew, the point of view must be changed, so much so that the uncertainty as expressed by MacLeod et al. [7] is that there can be a number of different consequences of a particular choice but the probabilities of these different outcomes are unknown.

Consequently, being unable to predict the results, to understand the system, to carry out any idea or those ideas' self-refutation of themselves might push the prospective teachers to uncertainty. At this point, the question of whether the prospective teachers have a high-level of teaching motivation and desire to teach in this uncertainty arises. In this regard, the need for defining the relationship between the attitude of prospective teachers towards uncertainty and their motivation in teaching comes in view.

The results of the research aiming to determine the effect of education students' attitudes towards uncertainty on their motivation in teaching as they are teachers of the future and can have both a router and decisive function for decision-makers and practitioners. By examining on what level prospective teachers' states of being uncertain affects their teaching motivation, this study will help to create awareness on this issue in relevant institutions and organizations. Additionally, the obtained results will contribute to the planning of psychological assistance to be able to be given to career counseling services for prospective teachers.

\section{The Purpose of the Study}

The overall objective of this study is to determine the relationship between prospective teachers' attitudes towards uncertainty and their motivation in teaching. For this purpose, answers are sought out for the following questions:

1. On what levels are prospective teachers' attitudes towards uncertainty and their motivation in teaching?

2. Is there a significant relationship between prospective teachers' attitudes towards uncertainty and their motivation in teaching?

3. Do prospective teachers' attitudes towards uncertainty predict their motivation in teaching significantly?

\section{Method}

\subsection{Research Design}

This research is a descriptive study designed with a relational screening model. Relational screening models are research models which aim to determine the existence and/or degree of joint variation between two or more variables [8]. In this study, this model's exploratory correlation and 
predictive correlation patterns were used. Exploratory correlation research is used to understand an important event by analyzing the relationships between variables. In predictive correlation research, by examining relationships between variables, the unknown value of other variable is tried to be determined as starting from one of the variables [9]. In this study, the relationship between the teachers' attitudes toward uncertainty and their teaching motivation were depicted as they existed.

\subsection{Research Sample}

The population of the research consists of 801 fourth grade students studying at the Inonu University Faculty of Education in the academic year of 2015-2016. The fourth grade Faculty of Education students' being the closest individuals to the teaching profession became influential on determining the population. In the research, not following the method of sample selection, the entire population was addressed in practice, but only 409 of them (51.1\%) were involved in the study. After the invalid data were considered (usually left blank, marked by the same option for all substances) and removed from the data set, the number of remaining participants was $396(49.4 \%)$. When compared with the sample size $(n=260)$ found as the result of Cochran's formula used for calculating population, this number was considered to be sufficient [10].

The distribution by gender and department of prospective teachers participating in the study are shown in Table 1.

Table 1. Personal characteristics of prospective teachers.

\begin{tabular}{lcc}
\hline Gender & $\boldsymbol{n}$ & $\mathbf{\%}$ \\
\hline Male & 123 & 31.1 \\
Female & 273 & 68.9 \\
\hline Department & $\boldsymbol{n}$ & $\mathbf{\%}$ \\
\hline Teaching art & 11 & 2.8 \\
Pre-school teaching & 56 & 14.1 \\
Counseling and guidance & 37 & 9.3 \\
Computer education and instructional technologies & 25 & 6.3 \\
Teaching science & 33 & 8.3 \\
Primary school teaching & 71 & 17.9 \\
Teaching English & 29 & 7.3 \\
Teaching Turkish & 12 & 3 \\
Teaching social sciences & 25 & 6.3 \\
Teaching of mentally handicapped & 33 & 8.3 \\
Teaching music & 13 & 3.3 \\
Mathematics teaching & 51 & 12.9 \\
\hline Total & 396 & 100 \\
\hline
\end{tabular}

When the distribution of personal characteristics of prospective teachers participating in the survey was examined, it was observed that $68.9 \%$ of them were male and $31.1 \%$ of them were female. The distribution of departments studied by prospective teachers shows that primary school teacher candidates (17.9\%) are the most represented among all the teaching branches in the study. The prospective teachers studying at the department of Art Teaching have the least number with a rate of $2.8 \%$.

\subsection{Data Collection Tools}

As data collection tools, two scales were used in this study. The first one of the scales applied simultaneously to the prospective teachers was "Attitude towards Uncertainty Scale" with the aim of measuring prospective teachers' attitudes towards uncertainty; another was "Motivation in Teaching Scale" with the aim of measuring the perception of motivation in teaching. 
Attitude towards Uncertainty Scale (ATUS) is a scale developed by Ersanlı and Uysal [11] that was aimed to reveal the level of uncertainty of prospective teachers studying at the Faculty of Education. In the process of developing the scale, the compliance of factor analysis of the data obtained from the first application was examined via Kaiser-Meyer-Olkin (KMO) test and Bartlett's test of sphericity. The KMO value was found to be 0.919 , Bartlett's test of sphericity was found to be meaningful $\left[\mathrm{x}^{2}=5079.703, \mathrm{df}=780\right.$, $p<0.001]$, and the data was found to be suitable for analysis. The scale is composed of one dimension and 15 items. The items forming the scale contain negative attitudes. As a Likert type scale with five points, ATUS's factor load was in the range between 0.57 and 0.78. In the scale, (5) refers to the "Most" preferred level, while (1) refers to the "Least" preferred level. The fit indices were found to be as $\left(\chi^{2}=191.78, \mathrm{df}=89\right.$, $\chi^{2} / \mathrm{df}=2.15$, RMSEA (Root Mean Square Error of Approximation) $=0.062$, GFI (Goodness of Fit Index) $=0.92$, AGFI (Adjusted Goodness of Fit Index) $=0.90$, RMR (Root Mean squared Residual) $=0.064$, CFI (Comparative Fit Index) $=0.93$ ) and the model was observed to have a good compliance. The internal coefficient of consistence was found to be $\alpha=0.89$. In this study, the Cronbach alpha internal coefficient of consistence of the scale was found to be 0.95 . The lowest score which could be obtained from the scale was 15 , and the highest score was 75 . To be able to evaluate on the basis of the scale, the score interval between 15 and 34 was accepted as "low", 35 and 54 as "medium", and 55-75 as "high".

Motivation in Teaching Scale (MTS) is a scale developed by Kauffman et al. and was adapted to Turkish by Ayık, Akdemir and Seçer [12,13]. High scores obtained from the scale indicate having a high level of motivation in teaching; on other hand, low scores indicate low level of motivation in teaching. To test the appropriateness of the data collected from study group to the factor analysis, $\mathrm{KMO}$ and Barlett tests were conducted. The value of KMO was found to be 0.836 and Bartlett test $\chi^{2}$ value was $1242.822(p<0.001)$ and it was proven to be suitable for the data analysis. At the end of the factor analysis implemented in the process of the scale's development, a dual-factor structure emerged explaining $52.4 \%$ of the total variance. There are six items each in the factors called as "Intrinsic Motivation" (IM) and "Extrinsic Motivation" (EM). On the scale each item has a Likert type scale with five point ratings ( $1=$ strongly disagree, $5=$ totally agree). The Cronbach's alpha internal consistency coefficients of the factors were found respectively 0.70 and 0.76 and were calculated as 0.84 for the whole MTS. Confirmatory factor analysis results suggest the model works well $\left(\chi^{2}=113.73, \mathrm{df}=51\right.$, $\chi^{2} / \mathrm{df}=2.23, \mathrm{RMSEA}=0.064, \mathrm{RMR}=0.010, \mathrm{NFI}$ (Normed Fit Index) $=0.95$, NNFI (Nonnormed Fit Index $)=0.96$, CFI $=0.97$, IFI (Incremental Fit Index $)=0.97$, RFI (Relative Fit Index) $=0.93$, GFI $=0.94$, AGFI $=0.90$ ). Nevertheless, the Cronbach's alpha internal consistency coefficient was found to be as 0.84 in this study, 0.77 for the factor of intrinsic motivation, 0.71 for the factor of extrinsic motivation. The lowest score that could be taken from the whole scale "MTS" was 12 and the highest score was 60. While the evaluations were being made, the scores in the range of 12-27 were regarded as "low", the scores in the range of 28-43 as "medium", and the scores in the range of 44-60 as "high" for MTS. As the number of items were the same for IM and EM subscales, the lowest score could be taken from both sub-scales was six, while the highest score was 30 . While the evaluations were being made, the scores in the range of 6-13 were regarded as "low", the scores in the range of 14-21 as "medium", and the scores in the range of $22-30$ as "high" for EM and IM.

\subsection{Data Analysis}

In order to determine prospective teachers' personal characteristics, levels of motivation in teaching, and attitudes towards uncertainty, descriptive statistics such as frequency, percentage, arithmetic mean, and standard deviation were calculated. In the study, to test the normality of data distribution, the Kolmogorov-Smirnov test, skewness-kurtosis coefficients, and histogram charts were examined and the distribution of the data ranged closely to normal, so the necessity of applying parametric tests was decided. With the aim of determining the relationship between motivation in teaching and attitudes toward uncertainty, correlation coefficients were calculated through Pearson Product Moment analysis which is a parametric test. The scattering diagram was examined to determine whether this relationship was linear and it was observed that there was a negative linear 
relationship. A simple linear regression analysis was conducted on the obtained data on the purpose of figuring out whether prospective teachers' attitudes towards uncertainty (independent) predict significantly their motivation in teaching (dependent).

\section{Results}

This section contains the findings associated with prospective teachers' attitudes towards uncertainty and the level of their motivation in teaching.

\subsection{Findings Associated with Prospective Teachers' Attitudes towards Uncertainty and the Level of Their Motivation in Teaching}

The distribution of statistics for prospective teachers' attitudes towards uncertainty and the level of their motivation in teaching is given in Table 2.

Table 2. Descriptive statistics on prospective teachers' attitudes towards uncertainty and the level of teaching motivation.

\begin{tabular}{cccccc}
\hline Scales and Sub Scales & $\boldsymbol{n}$ & $\overline{\mathbf{X}}$ & sd & Min & Max \\
\hline ATUS & 396 & 47.53 & 13.24 & 16.0 & 75.0 \\
MTS & 396 & 36.20 & 8.78 & 15.0 & 57.0 \\
IM & 396 & 18.50 & 5.06 & 6.0 & 29.00 \\
EM & 396 & 17.70 & 4.63 & 6.0 & 28.00 \\
\hline
\end{tabular}

Attitude towards Uncertainty Scale (ATUS), Motivation in Teaching Scale (MTS), Intrinsic Motivation (IM), Extrinsic Motivation (EM), Frequencies (n), Means ( $\bar{X})$, Standard Deviations (sd).

As shown in Table 2, when the descriptive statistics related to ATUS, MTS, and sub-dimensions of MTS were examined, it was seen that prospective teachers' mean scores were respectively $\bar{X}=47.53$ for ATUS, $\bar{X}=36.20$ for MTS, $\bar{X}=18.50$ for IM, and $\bar{X}=17.70$ for EM. Due to the fact that the means of the scores taken from scales and the subscales are in the range of "35-54" for ATUS, "28-43" for MTS, "14-21" for EM and IM, it can be said that prospective teachers' attitudes towards uncertainty, their motivation in teaching, intrinsic motivation, and extrinsic motivation were at the level "medium". In addition to this, the mean scores of prospective teachers' intrinsic motivation are determined to be higher by a slight difference than the mean scores of their extrinsic motivation.

\subsection{Findings Associated with Determining Prospective Teachers' Attitudes towards Uncertainty and Motivation in Teaching}

In order to determine the relationship between prospective teachers' attitudes towards uncertainty and the level of their motivation in teaching, Pearson's correlation coefficient was calculated and the distribution is given in Table 3.

Table 3. Correlations between prospective teachers' attitudes towards uncertainty and motivation in teaching.

\begin{tabular}{cccccc}
\hline & & $\begin{array}{c}\text { Attitudes towards } \\
\text { Uncertainty }\end{array}$ & $\begin{array}{c}\text { Motivation } \\
\text { in Teaching }\end{array}$ & $\begin{array}{c}\text { Intrinsic } \\
\text { Motivation }\end{array}$ & $\begin{array}{c}\text { Extrinsic } \\
\text { Motivation }\end{array}$ \\
\hline Attitudes Towards & $\mathrm{r}$ & 1 & $-0.484^{*}$ & $-0.428^{*}$ & $-0.450 *$ \\
Uncertainty & $\mathrm{p}$ & & 0.000 & 0.000 & 0.000 \\
\hline & Correlation coefficient (r), significantly correlated $(\mathrm{p}),{ }^{*} p<0.01$.
\end{tabular}

By examination of Table 3 it is seen that there is a moderate significant relationship in a negative direction $(r=-0.484, p<0.01)$ between prospective teachers' attitudes towards uncertainty and their teaching motivation. There is a moderate significant relationship on negative direction $(r=-0.428$, $p<0.01$ ) between prospective teachers' attitudes towards uncertainty and their intrinsic motivation; 
and there is a moderate significant relationship on negative direction $(\mathrm{r}=-0.450, p<0.01)$ between prospective teachers' attitudes towards uncertainty and their extrinsic motivation.

\subsection{Findings Associated with Regression Analysis of the Effect of Prospective Teachers' Attitudes towards Uncertainty on Their Motivation in Teaching}

In order to determine the state which prospective teachers' attitudes towards uncertainty predicts the level of their teaching motivation, simple linear regression analysis was conducted and the distribution is given in Table 4 .

Table 4. Simple linear regression analysis values associated with prediction of prospective teachers' motivation in teaching.

\begin{tabular}{ccccccccc}
\hline $\begin{array}{c}\text { Independent } \\
\text { Variable }\end{array}$ & $\mathbf{R}$ & $\mathbf{R}^{2}$ & $\mathbf{F}$ & $\mathbf{B}$ & $\begin{array}{c}\text { Standard } \\
\text { Error }\end{array}$ & $\boldsymbol{\beta}$ & $\mathbf{t}$ & $\mathbf{p}$ \\
\hline $\begin{array}{c}\text { Fixed Variable } \\
\text { Attitudes Towards } \\
\text { Uncertainty }\end{array}$ & 0.484 & 0.234 & 120.54 & -0.401 & 0.037 & -0.484 & -10.97 & 0.000 \\
\hline
\end{tabular}

Correlation coefficient $(R)$, proportion variance explained $\left(R^{2}\right)$, significance level $(F)$, unstandardised regression coefficient (B), standardised regression coefficient $(\beta)$, obtained $t$-value $(t)$, probability $(p)$. Dependent variable: motivation in teaching; $n=395$.

Table 4 shows according to the results of simple linear regression analysis done to reveal how prospective teachers' attitudes towards uncertainty predict their motivation in teaching, a significant relationship was observed between attitudes toward uncertainty and motivation in teaching $(R=0.484$, $\left.R^{2}=0.234\right)$, and the attitude towards to uncertainty was observed to be a significant predictor of motivation in teaching $(\mathrm{F}=120.54, p<0.01)$. Attitude towards uncertainty explains $23 \%$ of variation in motivation in teaching. When standardized $\beta$ coefficient was examined, it can be said that one unit change in attitude towards uncertainty may cause a change $(-0.484)$ in negative direction in motivation in teaching.

The regression analysis results associated with the fact that the attitudes towards uncertainty predicts intrinsic motivation which is a subscale of teaching motivation is given in Table 5 .

Table 5. Simple linear regression analysis values associated with prediction of prospective teachers' intrinsic motivation.

\begin{tabular}{ccccccccc}
\hline $\begin{array}{c}\text { Independent } \\
\text { Variable }\end{array}$ & $\mathbf{R}$ & $\mathbf{R}^{2}$ & $\mathbf{F}$ & $\mathbf{B}$ & $\begin{array}{c}\text { Standard } \\
\text { Error }\end{array}$ & $\boldsymbol{\beta}$ & $\mathbf{t}$ & $\mathbf{p}$ \\
\hline $\begin{array}{c}\text { Fixed Variable } \\
\text { Attitudes Towards } \\
\text { Uncertainty }\end{array}$ & 0.428 & 0.184 & 88.60 & -0.409 & 0.043 & -0.428 & -9.41 & 0.000 \\
\hline
\end{tabular}

Correlation coefficient $(\mathrm{R})$, proportion variance explained $\left(\mathrm{R}^{2}\right)$, significance level $(\mathrm{F})$, unstandardised regression coefficient $(B)$, standardised regression coefficient $(\beta)$, obtained $t$-value $(t)$, probability $(p)$. Dependent variable: intrinsic motivation; $n=395$.

Table 5 shows according to regression analysis results targeted to find how the prospective teachers' attitudes towards uncertainty predicts their intrinsic motivation which is subscale of teaching motivation, a significant relationship was observed between attitudes towards uncertainty and intrinsic motivation ( $\left.R=0.428, R^{2}=0.234\right)$; attitudes towards uncertainty was seen to be a significant predictor of intrinsic motivation $(\mathrm{F}=88.60, p<0.01)$. Attitudes towards uncertainty explain $18 \%$ of variation in the intrinsic motivation. When standardized $\beta$ coefficient was examined, it can be said that one-unit change in attitude towards uncertainty may cause a change $(-0.428)$ in a negative direction on intrinsic motivation. 
Regression analysis results associated with the fact that the attitudes towards uncertainty on extrinsic motivation which is subscale of motivation in teaching is given in Table 6.

Table 6. Simple linear regression analysis values associated with prediction of prospective teachers' extrinsic motivation.

\begin{tabular}{ccccccccc}
\hline $\begin{array}{c}\text { Independent } \\
\text { Variable }\end{array}$ & $\mathbf{R}$ & $\mathbf{R}^{\mathbf{2}}$ & $\mathbf{F}$ & $\mathbf{B}$ & $\begin{array}{c}\text { Standard } \\
\text { Error }\end{array}$ & $\boldsymbol{\beta}$ & $\mathbf{t}$ & $\mathbf{p}$ \\
\hline $\begin{array}{c}\text { Fixed Variable } \\
\text { Attitudes Towards } \\
\text { Uncertainty }\end{array}$ & 0.450 & 0.202 & 99.92 & -0.393 & 0.039 & -0.450 & -9.99 & 0.000 \\
\hline
\end{tabular}

Correlation coefficient $(R)$, proportion variance explained $\left(R^{2}\right)$, significance level $(F)$, unstandardised regression coefficient $(B)$, standardised regression coefficient $(\beta)$, obtained $t$-value $(t)$, probability $(p)$. Dependent variable: extrinsic motivation; $n=395$.

Table 6 shows according to regression analysis results targeted to find how the prospective teachers' attitudes towards uncertainty predicts their extrinsic motivation which is subscale of teaching motivation, there was a significant relationship between attitude towards uncertainty and extrinsic motivation ( $\left.R=0.450, R^{2}=0.202\right)$; attitude towards uncertainty is a significant predictor of extrinsic motivation ( $F=99.92, p<0.01)$. Attitude towards uncertainty explains $20 \%$ of variation in the extrinsic motivation. When standardized $\beta$ coefficient was examined, it can be said that a one-unit change in attitude towards uncertainty may cause a change $(-0.450)$ in a negative direction on extrinsic motivation.

\section{Discussion}

In this study, the prospective teachers' attitudes towards uncertainty are at a moderate degree. The scale used to determine this contains items related to negative attitudes towards uncertainty, which shows prospective teachers' attitudes towards uncertainty are negative at a moderate degree. Because individuals do not have knowledge about the future, the ones showing positive attitudes towards uncertainty shape their behaviors by thinking about how the decisions they make and choices they go for may come to a conclusion rather than how they end in, so in their present time, they organize and make use of the situations they may face in the future on their minds [14]. Individuals with a high tolerance for ambiguity are stated to be more successful and willing in solving complex problems, while those with less tolerance for ambiguity tend to escape from these kind of problems [15]. However, Sargut [16] stated that individuals significantly have a tendency to avoid uncertainty in Turkish culture. Macit [17] also concluded that the female and male students' average rate of avoidance from uncertainty is high in the research that he conducted on university students. In their research aiming to determine the level of uncertainty avoidance of prospective teachers studying at variable departments of the Education Faculty in terms of different variables, Korkut and Keskin [18] found that the participants' level of uncertainty avoidance was at a moderate degree. Uncertainty avoidance is considered equivalent to a show of negative attitudes towards uncertainty. Thus, the results of these studies are consistent with this study's result "that prospective teachers' attitudes towards uncertainty are negative at a moderate degree". It was stated that knowing prospective teachers' attitude towards a particular topic will be helpful, especially for decision-makers and practitioners to take the necessary measures to solve the problems [19]. Hence, it might be said that the present study in which the prospective teachers' attitudes towards uncertainty is determined to be significantly negative, is likely to bring important contributions to resolving the problems encountered in this area.

In this study, it was determined that teaching and the intrinsic and extrinsic motivation of the prospective teachers were at a moderate degree. Aylk and Ataş [20] also found that prospective teachers' motivation in teaching is at a moderate degree. In Sözen's [21] research, it was stated that motivation levels of English teachers working in primary and secondary schools in Turkey was low. As having an contradictory aspect to this result, in Ergen's study, the motivation levels of primary school teachers 
were found to be "largely satisfied" in terms of teachers' perceptions [22]. At the end of their research, Dereli and Acat stated that the prospective teachers' motivation for teaching profession was often high, and they experienced very few problems [23]. It was seen that the results of these studies identifying the level of motivation in teaching seem to vary. In the view of intrinsic and extrinsic motivation dimensions, in the study done by Ayık and Ataş [20], it was observed that prospective teachers had higher perceptions in dimension of intrinsic motivation than extrinsic motivation. In this study, it was concluded that prospective teachers' intrinsic motivation was by a slight difference higher than their extrinsic motivation as well. Indicating that motivation sources have an effect on the profession of teaching and separating these resources as internal and external, in his study, Yazıc1 [24] stated that sources of intrinsic motivation were more effective than sources of extrinsic motivation. In light of these findings, prospective teachers' having high intrinsic motivation might be considered as the indicator that they will perform their jobs willingly and fondly and they will become successful at their profession.

At the end of the research, it was found that there was a moderate degree, negatively directed relationship between prospective teachers' attitudes towards uncertainty and their motivation in teaching; the attitude towards to uncertainty was observed to be a significant predictor of teaching motivation. This result indicates that prospective teachers' negative attitudes towards uncertainty affect negatively teaching motivation, namely, when the prospective teachers' level of uncertainty increases, their level of teaching motivation decreases. If there is uncertainty in people's lives, this situation creates a negative impact on both their psychological well-being and subjective well-being [25]. In a study, the level of life satisfaction of prospective teachers who study at their department in order not to be unemployed were found to be low and their depression scores were higher [26]. In the research carried out by Şar et al. [27] it was concluded that the levels of life satisfaction of the prospective teachers waiting to be appointed were low. Prospective teachers' efforts remaining inconclusive to be appointed and uncertainties experienced in appointment procedure were stated to bring about an emergence of despair and low level of life satisfaction. Indeed, Kırımoğlu [28] concluded that prospective teachers' thoughts about being unable to be appointed after graduation raises their level of desperation in his study. The fact that prospective teachers' despair scores were high was interpreted as the likelihood of their future-oriented expectations such as finding a job after graduation, appointment to the target profession to come true were low, and in this case when they think about the future, they experience greater despair. That the level of despair of the prospective teachers who chose their profession unwillingly and had low expectations for future were higher, and their levels of life satisfaction were lower, was stated in the results of various studies $[29,30]$. Besides, in the research of Şar et al. [27], it was found that when the levels of intolerance to uncertainty of prospective teachers waiting to be appointed increase, their levels of life satisfaction decrease. Additionally, prospective teachers' continuous experiences about uncertainty about dates and quotas in the process of teacher appointment conducted by the Ministry of Education were referred to increase their scores of intolerance to uncertainty in the study. Studying with university students in our country, Sarıçam [25] stated that individuals' level of intolerance to uncertainty affects negatively their level of happiness and this situation led to a long-term anxiety problem in his study. There is also research results showing a positive correlation between intolerance with high anxiety and concern [31,32]. In addition to these studies, it was stated that individuals who are able to show a positive attitude towards uncertainty can enact their willpower to do their job as an inner attitude by putting anxiety and concern aside [33]. In his research Tinaztepe [34] confirmed that the perception of uncertainty explains significantly the emotional well-being of the employees on work. These inferences illustrate the impact of uncertainty on motivation. This situation supports the research conclusion that "the attitude towards uncertainty is a significant predictor of teaching motivation". Uncertainty, which was indicated to increase the level of prospective teachers' anxiety, concern, and despair in the results of other research, was put into the literature with the result of its reducing effect on motivation in teaching. 
Additionally, stating that there is a negatively significant relationship at a moderate degree between prospective teachers' attitudes towards uncertainty and their intrinsic and extrinsic motivation, the research results show that the attitude towards uncertainty is a significant predictor of intrinsic and extrinsic motivation. According to this result, prospective teachers' negative attitudes towards uncertainty affects negatively both their intrinsic and extrinsic motivation. In the same way, positive attitudes are stated to trigger people's motivation for their jobs and tasks [35]. Motivation is related to many variables in the individual's internal and external world. These variables may affect positively or negatively the motivation of individuals [36,37]. One of these variables for prospective teachers is uncertainty in the outside world. As environmental factors, uncertainty might be seen as determinant of extrinsic motivation. The effect of uncertainty on extrinsic motivation appeared at the end of the research, too. In addition to this, the result that uncertainty also affects individuals' intrinsic motivation arising from their needs was reached in the research. This situation may be interpreted as increasing the level of motivation provided through the factors of extrinsic motivation may positively affect the motivation provided through the factors of intrinsic motivation as well. That is to say, internal and external factors are required to be in a quality completing each other in order to ensure motivation. In this regard, it can be said that ensuring only internal factors will not be sufficient to motivate prospective teachers without providing external factors such as uncertainty.

\section{Limitations}

This research is limited to 396 prospective teachers who were studying in the 4th (senior) grade of Inonu University Faculty of Education in the 2015-2016 academic year and the answers given by these prospective teachers to the questions on the scales.

\section{Conclusions}

Research results show prospective teachers' attitudes towards uncertainty are negative at a moderate degree. In addition to these results, in this study it was determined that teaching, intrinsic, and extrinsic motivation of the prospective teachers were at moderate degree. And also, in this study, it is concluded that prospective teachers' intrinsic motivation is by a slight difference higher than their extrinsic motivation as well.

In the research, it is found that there is a moderate degree, negatively directed relationship between prospective teachers' attitudes towards uncertainty and their motivation in teaching; the attitude towards uncertainty was observed to be a significant predictor of teaching motivation. This result indicates that prospective teachers' negative attitudes towards uncertainty affect negatively teaching motivation, namely, when the prospective teachers' level of uncertainty increases, their level of teaching motivation decreases.

Additionally, stating that there is a negatively significant relationship at a moderate degree between prospective teachers' attitudes towards uncertainty and their intrinsic and extrinsic motivation, the research results show that the attitude towards uncertainty was a significant predictor of intrinsic and extrinsic motivation.

According to these results, factors that may cause uncertainty in prospective teachers should be reduced or eliminated. Therefore, the teacher appointment may be built up to expected levels. Reformative works should be done on behalf of teacher employment. Student recruitment for teacher training programs should be approached with a different point of view within the context of supply/demand balance. Counseling services on uncertainty management should be provided to the prospective teachers. Factors motivating teachers and prospective teachers and the order of priority of these factors might be determined. The reflection of the state of uncertainty that the prospective teachers experience in the process of preparation for exams on prospective teachers' academic achievement might be investigated. The decrease or increase in the motivation of prospective teachers and teachers through various internal and external factors may also reflect on their classroom 
attitudes. Thus, the effects of their teaching motivation on students' attitudes and motivation in the classroom may be examined, too.

Author Contributions: Investigation, C.Ş.; Methodology, C.Ş.; Writing-review \& editing, C.Ş. and M.A.

Conflicts of Interest: The authors declare no conflict of interest.

\section{References}

1. Kaya, F.Ş.; Yıldız, B.; Yıldız, H. An evaluation of the motivation levels of primary school teachers in terms Herzberg's two-factor theory. Acad. Sigh. Int. Ref. Online J. 2013, 39, 1-18.

2. Topçuoğlu Ünal, F.; Bursalı, H. Turkish Teachers' Views about Motivation Factors. Mid. East. Afr. J. Educ. Res. 2013, 5, 7-22.

3. Baum, L. Enthusiasm in teaching. Polit. Sci. Polit. 2002, 35, 87-90. [CrossRef]

4. Brophy, J. Motivating Students to Learn Second Edition; Lawrence Erlbaum Associates: London, UK, 2010.

5. Atkinson, E.S. An Investigation into the Relationship between Teacher Motivation and Pupil Motivation. Educ. Psychol. 2000, 20, 45-57. [CrossRef]

6. Grenier, S.; Barrette, A.M.; Ladouceur, R. Intolerance of uncertainty and intolerance of ambiguity: Similarities and differences. Pers. Individ. Dif. 2005, 39, 593-600. [CrossRef]

7. MacLeod, A.K.; Rose, G.S.; Williams, J.M.G. Components of hopelessness about the future in parasuicide. Cognit. Ther. Res. 1993, 17, 441-455. [CrossRef]

8. Karasar, N. Scientific Research Methods, 27th ed.; Nobel Academic: Ankara, Turcky, 2014.

9. Büyüköztürk, Ş.; Kılıç Çakmak, E.; Akgün, Ö.E.; Karadeniz, Ş.; Demirel, F. Introduction to Research Methods; Pegem Academi: Ankara, Turcky, 2013.

10. Cochran, W.G. Sampling Techniques, 3rd ed.; John Wiley Sons Inc: New York, NY, USA, 1977.

11. Ersanl, K.; Uysal, E. Developping attitudes toward uncertainty scale. Electron. J. Social Sci. 2015, 14, 46-53.

12. Kauffman, D.F.; Yilmaz Soylu, M.; Duke, B. Validation of the Motivation to Teach Scale. Hacettepe Univ. J. Educ. 2011, 40, 279-290.

13. Ayık, A.; Ataş Akdemir, Ö.; Seçer, İ. Adaptation of the Motivation to Teach Scale into Turkish: The Validity and Reliability Study Abstract. Curr Res. Educ. 2015, 1, 33-45.

14. Arıöz, Ö. Analysis of decision making process under uncertainty: An application example in cement industry in Turkey. Doctoral Dissertation, Anadolu University Institute of Social Sciences, Eskişehir, 6 February 2012.

15. Karavardar, G. Corporate governance, delegation of authority and tolerance for uncertainty in family businesses. Selçuk Uni. Inst. J. Social Sci. 2011, 1, 157-179.

16. Sargut, A.S. Cultural Diversity and Management; Ankara Verso Publ: Ankara, Turkey, 1994.

17. Macit, G. Effect of cultural values on communication styles: A study on Mehmet Akif Ersoy University students. Master's Thesis, Mehmet Akif Ersoy University Institute of Social Sciences, Isparta, 13 January 2010.

18. Korkut, A.; Keskin, I. A comparative analysis regarding uncertainty avoidance of pre-service teachers. EIJEAS 2015, 1, 31-57.

19. Akdağ, M. The reasons for information technologies pre-service teachers to prefer teaching profession and their attitudes towards the profession. Educ. Res. Rev. 2013, 8, 1499-1508.

20. Ayık, A.; Ataş, Ö. The relationship between pre-service teachers' attitudes towards the teaching profession and their motivation to teach. J. Educ. Sci. Res. 2014, 4, 25-43. [CrossRef]

21. Sözen, N. An investigation of efl teachers' perceptions on motivational factors. Master's Thesis, Middle East Technical University the Graduate School of Social Sciences, Ankara, January 2015.

22. Ergen, Y. The Effects of instructional Leadership Behaviors of Primary School Principals? On Teachers? Motivation (The case of Manisa). Master's Thesis, Celal Bayar University Institute of Social Sciences, Manisa, 11 October 2009.

23. Dereli, E.; Acat, M.B. Motivation Source and Problems Relative Teacher Occupation of Preschool Education Teacher Department Students. Selcuk Univ. Soc. Sci. Inst. J. 2010, 24, 174-187.

24. Yazıc1, H. Teaching Profession Sources of Motivation and Basic Attitudes: A Theoretical Overview. Kastamonu Univ. Kastamonu Educ. J. 2009, 17, 33-46.

25. Sarıçam, H. The effect of intolerance of uncertainty on happiness. J. Social Sci. 2014, 4, 1-12. 
26. Gündoğar, D.; Gül, S.S.; Uskun, E.; Demirci, S.; Keçeci, D. Investigation of the predictors of life satisfaction in university students. Klin. Psikiyatr. 2007, 10, 14-27.

27. Şar, A.H.; Işıklar, A.; Aydoğan, İ. The examination of variables that predict life satisfaction of teacher candidates waiting for assignment. Mehmet Akif Ersoy Univ. J. Educ. Fac. 2012, 12, 257-271.

28. Kırımoğlu, H. The study of hopelessness levels of final year students of the department of physical education and sports in turkey in terms of employment matter. Kastamonu Uni. Kastamonu Educ. J. 2010, 18, 37-46.

29. Ceyhan, A.A. Investigation of hopelessness levels of prospective teachers attending non-thesis master programs. Anadolu Uni. J. Social Sci. 2004, 4, 91-102.

30. Gencay, S. Examination of hopelessness and life satisfaction level of physical educator candidates according to the some variables. Soc. Sci. 2009, 8, 380-388.

31. Koerner, N.; Dugas, M.J. An investigation of appraisals in individuals vulnerable to excessive worry: The role of intolerance of uncertainty. Cognit. Ther. Res. 2008, 32, 619-638. [CrossRef]

32. Sarl, S. The investigation of intolerance of uncertainty, beliefs about worrry and locus of control as predictors of trait anxiety. Master's Thesis, Hacettepe University Institute of Social Sciences, Ankara, 05 September 2007.

33. Özcan, R. Impacts of uncertainty avoidance on organizational communication: An applied research on military administrators. Master's Thesis, Baskent University Institute of Social Sciences, Ankara, 19 March 2003.

34. Tinaztepe, $\mathrm{C}$. The effect of desire for change on the relationship between perceived uncertainty and job related affective well being. Master's Thesis, Marmara University Institute of Social Sciences, İstanbul, 30 July 2010.

35. Kara, A. The development of the scale of attitudes toward learning. J. Social Sci. 2010, 9, 49-62.

36. Small, R.V. Motivation in Instructional Design. ERIC Clear. Inf. Technol. Syracuse 1997, 24, 89-92.

37. Yazıc1, H. Motivation. In Educational Psychology, 1st ed.; Pegem Academi: Ankara, Turkey, 2008.

(C) 2018 by the authors. Licensee MDPI, Basel, Switzerland. This article is an open access article distributed under the terms and conditions of the Creative Commons Attribution (CC BY) license (http:/ / creativecommons.org/licenses/by/4.0/). 